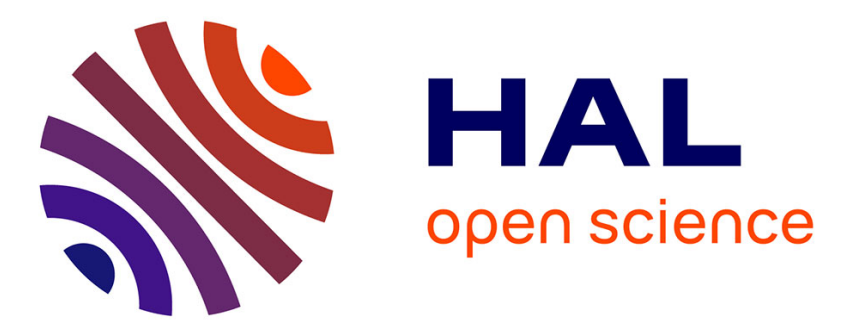

\title{
Porous diamond pouch cell supercapacitors
}

Emmanuel Scorsone, Nouha Gattout, Lionel Rousseau, Gaelle Bazin

Lissorgues

\section{To cite this version:}

Emmanuel Scorsone, Nouha Gattout, Lionel Rousseau, Gaelle Bazin Lissorgues. Porous diamond pouch cell supercapacitors. Diamond and Related Materials, 2017, 76, pp.31-37. 10.1016/j.diamond.2017.04.004 . cea-01803824

\section{HAL Id: cea-01803824 https://hal-cea.archives-ouvertes.fr/cea-01803824}

Submitted on 10 Jan 2019

HAL is a multi-disciplinary open access archive for the deposit and dissemination of scientific research documents, whether they are published or not. The documents may come from teaching and research institutions in France or abroad, or from public or private research centers.
L'archive ouverte pluridisciplinaire HAL, est destinée au dépôt et à la diffusion de documents scientifiques de niveau recherche, publiés ou non, émanant des établissements d'enseignement et de recherche français ou étrangers, des laboratoires publics ou privés. 


\title{
Porous diamond pouch cell supercapacitors
}

Emmanuel Scorsone ${ }^{1 *}$, Nouha Gattout ${ }^{2}$, Lionel Rousseau ${ }^{2}$, Gaelle Lissorgues ${ }^{2}$

${ }^{1}$ CEA, LIST, Diamond Sensors Laboratory, 91191, Gif-sur-Yvette, France

${ }^{2}$ ESIEE - ESYCOM Université Paris Est, Cite Descartes, BP99, 93162 Noisy Le Grand, France

Email: emmanuel.scorsone@cea.fr

Tel: +33169086934

\begin{abstract}
Supercapacitors are promising energy storage devices because of fast charge and discharge capacity, long lifetime and high power sources when compared to conventional batteries. Most carbon based supercapacitors nowadays use organic or ionic liquid based electrolytes in order to benefit from the large potential window in those solvents thus enabling more energy storage. However the devices suffer from low ionic mobility in such electrolytes, and also from economical, safety and environmental concerns associated with the use of organic solvents. Boron doped diamond (BDD) features a wide potential window in aqueous electrolytes and high stability toward oxidation in acidic or alkaline media, and therefore offers the possibility for BDD electrodes supercapacitor to operate in water. Here highly porous diamond electrodes fabricated by microwave plasma chemical vapor deposition of BDD over a conductive polypyrrole template with high double layer capacitance around 3 mF.cm ${ }^{-2}$ were mounted in symmetrical pouch cell supercapacitor using either $1 \mathrm{M} \mathrm{H}_{2} \mathrm{SO}_{4}$ or $1 \mathrm{M} \mathrm{TEABF} 4$ in propylene carbonate electrolytes. The performances of both devices were investigated. Energy and power values close to $1 \mu \mathrm{Wh} . \mathrm{cm}^{-2}$ and $700 \mu \mathrm{W} . \mathrm{cm}^{-2}$ were recorded in water, thus surpassing by almost one order of magnitude the energy storage performances of the device using organic electrolyte.
\end{abstract}

\section{Introduction}

The beginning of the $21^{\text {st }}$ century has seen a radical change in our way of living with the arrival of multifunction portable electronic devices including smartphones, tablets, etc. In such mobile equipment, wireless communication, touch pads or embedded sensors are functions that all contribute to the need for both compact and efficient energy storage. Nowadays this is achieved mostly by thin film technologies based rechargeable micro- 
batteries. Nevertheless, these batteries generally suffer from poor cycle lifetime and poor low temperature kinetics [1]. Thus the design of miniaturized energy-storage devices, with the capacity for autonomous recharging through energy harvesting, along with the ability to deliver high energy for the lifetime of the equipment being powered, remains a real challenge. Supercapacitors or electric double layer capacitors (EDLC) are energy storage devices with high specific energy when compared to conventional capacitors [2]. Thin film supercapacitors are seen as a promising alternative to batteries in portable electronic devices, because in supercapacitors energy is stored and released by transferring surface charges, meaning that they can be charged and discharged rapidly. Because the electrode materials are not involved in any chemical reactions, they can be cycled hundreds of thousands of times [3]. Three types of supercapacitors may be distinguished: carbon/carbon [4, 5, 6], metal oxide [7] and electronically conducting polymers [8]. Metal oxide supercapacitors are generally expensive or feature low conductivity whereas conductive polymers have been reported to exhibit short cycling life [9]. In contrast, carbon electrodes are low cost, and they possess superior combination of chemical and physical properties including high conductivity, high temperature stability, high versatility in structure/texture, and high specific surface area [5]. For these reasons, most of the currently available supercapacitors on the market are based on activated carbon electrodes in an organic electrolyte. But although symmetrical carbon/carbon electrodes in organic electrolyte is now mature, it can still be improved by developing better active carbon electrodes and/or electrolyte formulations.

An important feature in supercapacitors is their potential window, since both energy storage and power release depend on this parameter, according to the well-known equations $\mathrm{E}=1 / 2 \mathrm{CV}^{2}$ and $\mathrm{P}=\mathrm{V}^{2} / 4 \mathrm{ESR}$, where $\mathrm{C}, \mathrm{V}$ and $\mathrm{ESR}$ are the capacitance, the potential window, and the equivalent series resistance of the device, respectively [5]. When more active material is deposited onto the charge collector, more energy can be stored by the device, but then energy become more difficult to release [10]. Thus a good compromise needs to be found in terms of active material thickness. But generally speaking, an efficient way to increase both energy and power consists in enlarging the potential window, according to the above equations. One way to open the potential window is to use organic solvents, typically acetonitrile or propylene carbonate (PC), the practical opening voltage of organic electrolytes in symmetric carbon/carbon supercapacitors being around 2.7-2.8 V [11, 12]. However, this involves the need to ensure that no water traces are present in the solvent or the active electrode material, which brings some constrains in the fabrication process [13]. Moreover the low flash point of some solvents such as acetonitrile (below $5{ }^{\circ} \mathrm{C}$ ) may cause some safety

*Corresponding author. Email: emmanuel.scorsone@cea.fr (Emmanuel Scorsone) 
concerns [14]. Additionally, the low conductivity and low ionic mobility in such liquids lead to poor charge propagation inside the active electrode's pores. Ionic liquids have also been considered as a good alternative because of their low toxicity and flammability, high thermal stability, and wide voltage window typically around $4.5 \mathrm{~V}$ [15]. Unfortunately their high price and fairly low conductivity cannot satisfy the requirements for their use for large-scale supercapacitor applications [16]. This issue could be overcome using aqueous electrolytes but most carbon electrodes exhibit a narrow potential window in such media, where water starts to decompose from 0.7 to $0.8 \mathrm{~V}$ in typical acidic or basic electrolytes [17]. It was shown that neutral aqueous electrolytes such as alkali sulfates could achieve higher voltages with carbon/carbon supercapacitors than generally obtained in $\mathrm{KOH}$ or $\mathrm{H}_{2} \mathrm{SO}_{4}$ based electrolytes. For instance a practical voltage of $1.6 \mathrm{~V}$ was reached in symmetric carbon/carbon system using $0.5 \mathrm{M} \mathrm{Na}_{2} \mathrm{SO}_{4}$ [18], but this is still $1 \mathrm{~V}$ less than with organic electrolytes.

Boron doped diamond (BDD) is also considered as a promising alternative because of its significantly superior electrochemical properties when compared to other forms of carbon, including a wide potential window in aqueous media, and long term response stability [19]. These properties have recently led to some research to attempt to apply diamond in energy storage devices such as supercapacitors. Indeed, with a potential window exceeding $3 \mathrm{~V}$ in water, diamond is offering hope to make energy efficient aqueous based supercapacitors thus benefiting from the high ionic mobility in water. The high corrosion resilience even in harsh acidic or alkaline media is also expected to offer long cycling lifetime of such energy storage devices. Unfortunately, planar polycrystalline diamond electrodes exhibit low surface area and low intrinsic double layer capacitance, in the order of $5 \mu \mathrm{F} . \mathrm{cm}^{-2}$, which limit drastically energy storage. Nevertheless several successful developments have been reported recently to increase the surface area of diamond surfaces [20]. Some approaches have used top down processes in order to etch diamond and increase its porosity [21-25]. However, the relatively low conductivity of diamond, even when highly doped, generally results in electrodes with high series resistance. Therefore bottom up approaches have been preferred where diamond is grown on a porous template, ideally a good current collector. One approach has consisted of growing BDD on silicon nanowires. Such substrate was assess for supercapacitor application in ionic liquid [26]. A double layer capacitance of $105 \mu \mathrm{F} . \mathrm{cm}^{-2}$ was reported. Here the series resistance was fairly high, in the order of $200 \Omega$, most probably because of the high resistivity of the silicon nanowires and the electrolyte used. High surface area silica spheres [27] or fibers [28] template were also used. Both substrates led to similar results in terms of electrochemical performances. If the silica sphere template seemed more promising for

*Corresponding author. Email: emmanuel.scorsone@cea.fr (Emmanuel Scorsone) 
integration into small electronic devices, there was no data on the series resistance of the films, which affects drastically the performances of supercapacitor. A pouch cell device with silica fibers scaffold was built and showed some highly interesting performances in aqueous based electrolyte, despite the non-conducting template. The double layer capacitance of such films was in the order of $0.6 \mathrm{mF} . \mathrm{cm}^{-2}$ with a series resistance of $1.3 \Omega$. Recently alternative material consisting of BDD grown on highly porous carbon nanotubes [29] or polypyrrole templates [30] were reported. The latter diamond-coated template showed the best results in terms of double layer capacitance, up to $3 \mathrm{mF} . \mathrm{cm}^{-2}$, which is the highest value reported for diamond films to the author's knowledge. Moreover, in contrast with other types of porous diamond based materials, it can be processed homogeneously on 4 inches surfaces and thus offers a clear advantage in terms of manufacturing. However, it is known that 3electrode cell systems tend to overestimate the electrochemical capacitance of thin films, and this material was never tested in symmetrical configuration. Therefore in this paper, such porous diamond film, known as SPDia ${ }^{\mathrm{TM}}$, was integrated into a pouch cell supercapacitor and tested. The main objective of this work is to investigate this material for its supercapacitor performances in comparison with other diamond based electrode materials. The performances of the device were compared when organic and aqueous based electrolytes were used, since the main advantage of diamond for such application is the potentiality to use aqueous based electrolytes.

\section{Material and methods}

\subsection{Porous diamond film preparation}

All chemicals were purchased from Sigma Aldrich, France, unless specified, and used as received. Highly porous polypyrrole film was initially prepared as follows onto a highly conductive $\left(<0.005 \Omega . \mathrm{cm}^{-1}\right) 4$ inches $<100>$ silicon wafer, previously coated with a boron doped diamond thin film (thickness approx. $300 \mathrm{~nm}$, doping level $2.10^{21} \mathrm{~cm}^{-3}$ ) by Microwave Plasma Chemical Vapour Deposition (MPCVD) using a process described elsewhere [31]. Such substrate was used for convenience, and because it is compatible with the diamond growth conditions, but it could be replaced by a less resistive metal collection provided that it is also appropriate for diamond growth.

Firstly, a stock solution of $4 \mathrm{M} \mathrm{FeCl}_{3}$ dissolved in polyethylene glycol was prepared and stored in the dark at $4^{\circ} \mathrm{C}$ when not used. This solution was spin coated over the BDD coated *Corresponding author. Email: emmanuel.scorsone@cea.fr (Emmanuel Scorsone) 
silicon wafer at $3000 \mathrm{rpm}$ for $20 \mathrm{sec}$. The substrate was then placed in a sealed chamber and exposed to saturated pyrrole vapour in dry nitrogen at room temperature for $4 \mathrm{hrs}$. This way, pyrrole was polymerized in situ over the silicon substrate using $\mathrm{FeCl}_{3}$ as oxidizing agent/dopant [32]. Following polymerization, the samples were rinsed several times gently in acetonitrile until the wash solution became colourless, in order to remove the excess $\mathrm{FeCl}_{3}$ and polyethylene glycol. Finally the substrate was dried under nitrogen flow.

Next the substrate was dipped alternatively three times into an aqueous solution of poly(diallyldimethylammonium chloride) (PDDAC) and three times in a colloidal solution of nanodiamond $(0.1 \mathrm{wt} \%$ prepared in deionized water from Syndia SYP 0-0.02 GAF, Van Moppes, Switzerland) to electrostatically immobilize the nanoparticles onto the polymer template [30]. Boron doped diamond was then grown over the seeded substrate in a MPCVD reactor Seki AX6500 reactor in a gas mixture of $1 \% \mathrm{CH}_{4}$ in $\mathrm{H}_{2}$ with trimethylboron as the source of dopant, at microwave power of $3 \mathrm{~kW}$ and gas pressure of $20 \mathrm{mBar}$ for $3 \mathrm{hrs}$. A highly porous BDD film was obtained as described and characterized in ref [30]. A SEM image of the resulting polypyrrole film after diamond growth recorded using an in-lens Field Emission Scanning Electron Microscope ZEISS Supra-40, operating with an acceleration voltage of $5 \mathrm{kV}$, is shown in Fig.1.a. The thickness of the porous diamond film was measured to be approximately $15 \mu \mathrm{m}$. The weight of the porous film was measured gravimetrically and was found to be $31 \mathrm{mg} \cdot \mathrm{cm}^{-2}$.

The highly textured nature of the diamond film combined with its hydrogen terminated surface following CVD diamond growth result in a highly hydrophobic surface. Contact angle was measured to be in the order of $135^{\circ}$ after growth. The porous diamond film was therefore oxidized through a photochemical treatment under oxygen in order to increase wettability. During this process, low pressure oxygen (400 mbar) is exposed to UV light using a xenon excimer lamp $(172 \mathrm{~nm})$. This step involves oxygen radicals and ozone active species that react with the diamond surface. Following this oxidation treatment, contact angle was measured again and was found to be around $24^{\circ}$ (contact angle _ suppl.mat).

\subsection{Pouch cell fabrication}

The substrate was cleaved into $3 \mathrm{~cm}^{2}$ pieces. Electrical contacts were taken from the back side of two $3 \mathrm{~cm}^{2}$ SPDia ${ }^{\mathrm{TM}}$ coated silicon substrates by polishing gently the silicon substrate to remove the oxide layer and then fixing stainless steel strips to the substrate using silver loaded *Corresponding author. Email: emmanuel.scorsone@cea.fr (Emmanuel Scorsone) 
epoxy paste. Finally the contact area was covered with fast epoxy adhesive (Araldite ${ }^{\mathrm{TM}}$ ) in order to strengthen mechanically the contact and insulate any residual silver paste from the electrolyte solution. The 2 plates were then placed face to face and separated by glass microfiber filter (Whatman, Grade GF/D) soaked with electrolyte solution. The electrolyte was either aqueous $1 \mathrm{M} \mathrm{H}_{2} \mathrm{SO}_{4}$ or $1 \mathrm{M}$ tetraethylammonium tetrafluoroborate $\left(\mathrm{TEABF}_{4}\right)$ in propylene carbonate (PC). The electrodes assembly was finally packaged in soft plastic enclosure. A photograph of the pouch cell before and after assembly is shown in Fig.1b and Fig.1c, respectively.



*Corresponding author. Email: emmanuel.scorsone@cea.fr (Emmanuel Scorsone) 
Fig. 1 a, SEM images of the surface of SPDia ${ }^{\mathrm{TM}}$ material used as energy storage electrodes b, $3 \mathrm{~cm}^{-2}$ pouch cell supercapacitor before and c, after assembly

\subsection{Electrochemical characterization}

Electrochemical measurements were performed using a computer driven Autolab PGSTAT 302 potentiostat (Ecochemie BV). Cyclic voltammetry (CV) and AC-impedance measurements were carried out at room temperature. Impedance spectra were recorded over a $50,000-0.1 \mathrm{~Hz}$ frequency range with logarithmic point spacing and a potential amplitude of $0.01 \mathrm{~V}$ rms, while maintaining the working electrode at the open circuit potential (OCP).

\section{Results and discussions}

Cyclic voltammetry was initially performed to assess the potential window of the two devices with either organic or aqueous electrolytes. Diamond is known to be one of the materials that feature the highest potential window in water, typically above $3 \mathrm{~V}$. However, when grown over some substrates including carbon based substrates such as CNTs, this window is generally reduced. This is most probably due to the specific growth conditions used not to damage the substrate that possibly increase the $\mathrm{sp} 2$ carbon ratio, which tends to reduce the potential window. Here cyclic voltammetry was performed at $100 \mathrm{mV} . \mathrm{s}^{-1}$ with both devices, containing either PC or aqueous based electrolyte solution, while gradually opening the window from $0.6 \mathrm{~V}$ to $3 \mathrm{~V}$ in steps of $0.2 \mathrm{~V}$ (Fig.2). In the case of aqueous electrolyte (Fig.2a), at small potentials below typically $1.5 \mathrm{~V}$, no faradic process seems to be observed as CVs are almost symmetrical. Then water splitting starts to increase gradually. At $2.6 \mathrm{~V}$ the ratio of faradic current over capacitive current is still $<4$, due to the absence of electro catalytic processes at the diamond surface. Water decomposition behavior is comparable to symmetrical pouch cell made of BDD coated glass fiber electrodes [28] and occurs at slightly higher potential than symmetrical activated carbon supercapacitor using non acidic or alkaline electrolyte, which is known to widen the potential window overall [18]. As expected, no significant faradic process due to solvent decomposition seems to occur in the case of PC within the $3 \mathrm{~V}$ window, as shown in Fig.2b for comparison purpose. Fig.2c shows the *Corresponding author. Email: emmanuel.scorsone@cea.fr (Emmanuel Scorsone) 
Coulombic efficiency of the device, calculated via efficiency $=Q_{\text {discharging }} / Q_{\text {charging }}$ where $\mathrm{Q}_{\text {discharging }}$ and $\mathrm{Q}_{\text {charging }}$ are the amount of charge during charging and discharging process while running cyclic voltammetry. The efficiency at low voltages is approximately $85 \%$ and remains constant up to $3 \mathrm{~V}$ for PC. In the case of the aqueous electrolyte, its starts to decrease from typically $1.5 \mathrm{~V}$, in agreement with the observations made previously on the CVs and resulting from solvent decomposition. The non-rectangular shape of the CVs for low potential windows, as well as the fairly low efficiency at low voltages for water and across the whole potential window range for PC, both indicate a moderate charge-discharge process.
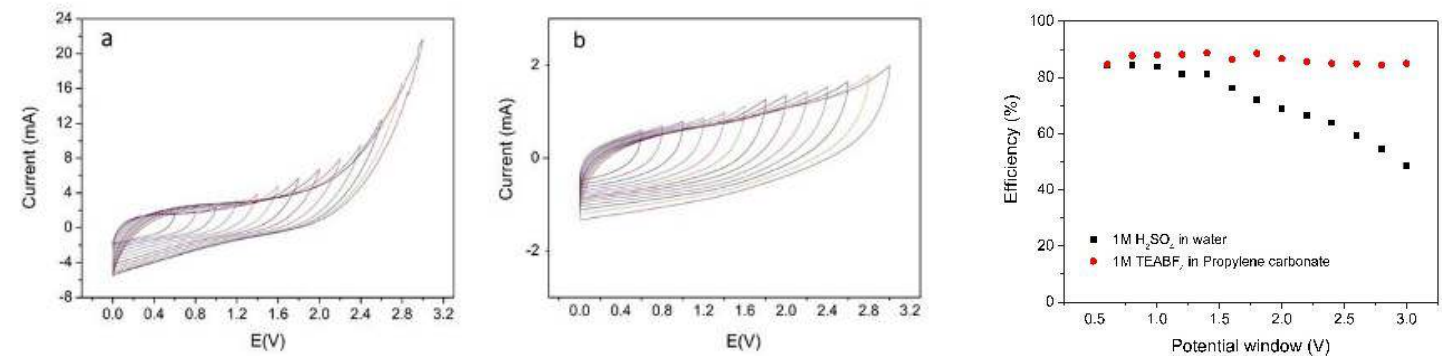

Fig.2. Opening window test from 0.6 to $3 \mathrm{~V}$ in steps of $0.2 \mathrm{~V}$, at a scan rate of $100 \mathrm{mV} . \mathrm{s}^{-1}$ for diamond pouch cell supercapacitor with a. $1 \mathrm{M} \mathrm{H}_{2} \mathrm{SO}_{4}$ in water and b. $1 \mathrm{M}$ TEABF 4 in $\mathrm{PC}$, as electrolytes. c. plot of the Coulombic efficiency of the device against the potential window

Cyclic voltammetry was also investigated in the potential window of $1 \mathrm{~V}$ to assess the performances of the pouch cells, while scanning at different scan rates from $10 \mathrm{mV} . \mathrm{s}^{-1}$ up to 100 V.s ${ }^{-1}$ (Fig.3). The CV curves of both symmetric capacitors retain a nearly rectangular shape and a rapid current response to voltage at each potential end and show low distortion even at high scan rates up to $100 \mathrm{~V} \cdot \mathrm{s}^{-1}$. This suggests a good capacitive behavior and fairly fast ionic diffusion into the porous diamond layer [33]. The small distortion observed at high scan rates may be due to the slightly high series resistance, as observed later on from EIS data, possibly attributed to the semiconducting nature of diamond, although highly doped. It may also imply some faradic processes, in particular in aqueous electrolyte. The areal capacitance for both electrolytes was derived from the CVs and graphed as a function of scan rates in Fig.4. The highest capacitance values obtained for the aqueous and PC based electrolytes at $10 \mathrm{mV} . \mathrm{s}^{-1}$ are $1.31 \mathrm{mF} . \mathrm{cm}^{-2}$ and $0.42 \mathrm{mF} . \mathrm{cm}^{-2}$, respectively. The maximum areal capacitance in aqueous electrolyte is in good agreement with the $3 \mathrm{mF} . \mathrm{cm}^{-2}$ value reported in $0.1 \mathrm{M} \mathrm{LiClO}_{4}$. The slightly higher value in the latter case may be explained by the fact that three-electrode measurement configuration has been reported to overestimate the *Corresponding author. Email: emmanuel.scorsone@cea.fr (Emmanuel Scorsone) 
capacitance value [34] and also by the use of different ionic salts. Also some variation may be observed according to the thickness of the diamond layer grown over polypyrrole [30]. In PC, the areal capacitance is significantly lower. This is attributed firstly to the higher dielectric constant as well as higher size of solvated ions in PC compared to water [5]. The capacitance values in aqueous and organic electrolytes are reported in Table 1 and compared to other porous diamond materials reported to date in the literature. The highest capacitance value $\left(1.83 \mathrm{mF} . \mathrm{cm}^{-2}\right)$ was measured on diamond honeycombs by Yoshimura and coworkers. Here the exceptionally high capacitance measured despite the fairly large pore size was explained by the needle-like structure at the bottom of the honeycomb pores as a result of the etching process. However, this result was obtained in a three-electrode configuration, which, as mentioned before, tends to overestimate the areal capacitance. The second highest value was obtained with SPDia ${ }^{\mathrm{TM}}\left(1.31 \mathrm{mF} . \mathrm{cm}^{-2}\right)$ this time in a symmetrical electrodes configuration. This value is significantly higher than diamond coated glass fibers, also in symmetrical electrode configuration $\left(0.7 \mathrm{mF} . \mathrm{cm}^{-2}\right)$, and much higher than any other reported porous diamond electrode materials even in aqueous electrolytes, to the author's knowledge.
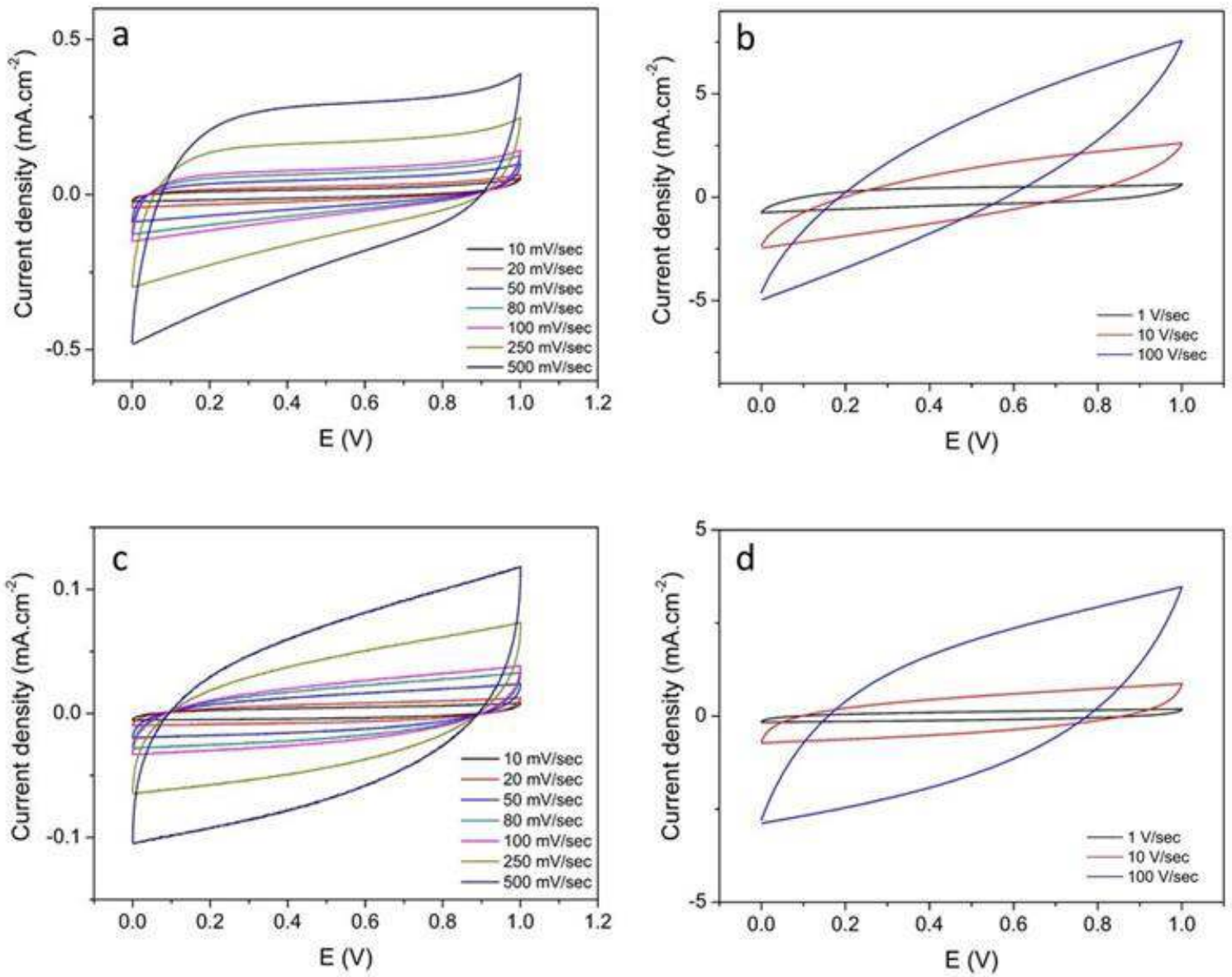

*Corresponding author. Email: emmanuel.scorsone@cea.fr (Emmanuel Scorsone) 
Fig.3. Cyclic voltammetry results from 0 to $1 \mathrm{~V}$ for scan rates varying from $10 \mathrm{mV} . \mathrm{s}^{-1}$ to 100 V.s ${ }^{-1}$ for diamond pouch cell supercapacitor with $1 \mathrm{M} \mathrm{H}_{2} \mathrm{SO}_{4}$ in water (a and b) and $1 \mathrm{M}$ $\mathrm{TEABF}_{4}$ in $\mathrm{PC}(\mathrm{b}$ and $\mathrm{c})$

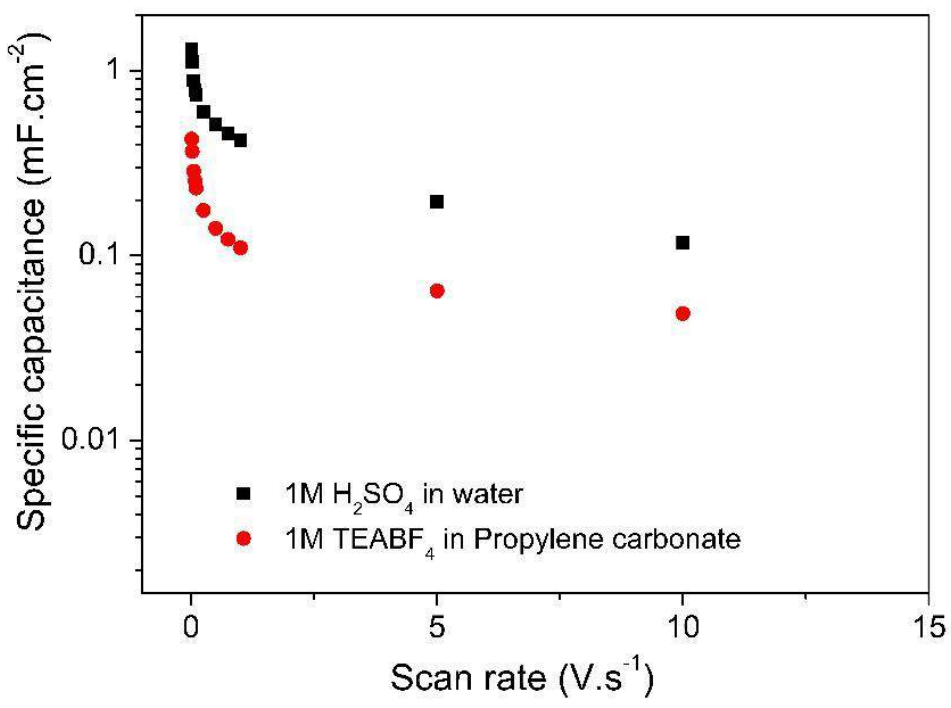

Fig.4. Specific capacitance of the diamond pouch cell at different scan rates from $10 \mathrm{mV} . \mathrm{s}^{-1}$ to $10 \mathrm{~V} . \mathrm{s}^{-1}$ for the aqueous and organic based electrolytes

Table 1. Comparison of areal capacitance values of our device with other state-of-the-art supercapacitor using porous diamond electrodes from the literature.

\begin{tabular}{|c|c|c|c|c|c|}
\hline & Electrolyte & Measurement type & $\begin{array}{c}\text { Areal } \\
\text { capacitance }\end{array}$ & Comments & references \\
\hline $\mathrm{SPDia}^{\mathrm{TM}}$ & $\begin{array}{l}0.5 \mathrm{M} \text { aqueous } \mathrm{H}_{2} \mathrm{SO}_{4} \\
0.5 \mathrm{M} \mathrm{TEABF} 4 \text { in } \mathrm{PC}\end{array}$ & $\mathrm{CV}\left(10 \mathrm{mV} \cdot \mathrm{s}^{-1}\right)$ & $\begin{array}{l}1.31 \mathrm{mF} . \mathrm{cm}^{-2} \\
0.42 \mathrm{mF} . \mathrm{cm}^{-2}\end{array}$ & $\begin{array}{c}\text { Symmetrical } \\
\text { electrode system }\end{array}$ & This work \\
\hline $\begin{array}{l}\text { BDD coated } \\
\text { Silicon } \\
\text { nanowire }\end{array}$ & $\begin{array}{l}\text { Bis(trifluoromethylsulfo } \\
\text { nyl) imide } \\
\text { (ionic liquid) }\end{array}$ & $\begin{array}{c}\mathrm{CV} \\
\left(5 \mathrm{mV} \cdot \mathrm{s}^{-1}\right)\end{array}$ & $317 \mu \mathrm{F} . \mathrm{cm}^{-2}$ & $\begin{array}{c}\text { Three electrodes } \\
\text { measurements }\end{array}$ & [39] \\
\hline $\begin{array}{l}\text { BDD coated } \\
\text { Glass fibers }\end{array}$ & $3 \mathrm{M}$ aqueous $\mathrm{NaClO}_{4}$ & Low frequency EIS & $0.7 \mathrm{mF} \cdot \mathrm{cm}^{-2}$ & $\begin{array}{c}\text { Symmetrical } \\
\text { electrode system }\end{array}$ & [28] \\
\hline $\begin{array}{c}\text { Nanoporous } \\
\text { honeycomb } \\
\text { diamond }\end{array}$ & $\begin{array}{l}1 \mathrm{M} \text { aqueous } \mathrm{H}_{2} \mathrm{SO}_{4} \\
0.5 \mathrm{M} \mathrm{TEABF} \\
4\end{array}$ & Low frequency EIS & $\begin{array}{l}1.83 \mathrm{mF} . \mathrm{cm}^{-2} \\
187 \mu \mathrm{F} . \mathrm{cm}^{-2}\end{array}$ & $\begin{array}{c}\text { Three electrodes } \\
\text { measurements } \\
\text { Pore size } 60 \mathrm{x} \\
500 \mathrm{~nm}\end{array}$ & [24] \\
\hline
\end{tabular}

*Corresponding author. Email: emmanuel.scorsone@cea.fr (Emmanuel Scorsone) 


\begin{tabular}{|c|c|c|c|c|c|}
\hline $\begin{array}{l}\text { Diamond } \\
\text { foam (silica } \\
\text { sphere } \\
\text { template) }\end{array}$ & $\begin{array}{l}3 \mathrm{M} \text { aqueous } \mathrm{NaClO}_{4} \\
40 \% \text { ionic liquid in } \mathrm{PC}\end{array}$ & $\mathrm{CV}\left(1 \mathrm{~V} \cdot \mathrm{s}^{-1}\right)$ & $\begin{array}{l}598 \mu \mathrm{F} . \mathrm{cm}^{-2} \\
436 \mu \mathrm{F} . \mathrm{cm}^{-2}\end{array}$ & $\begin{array}{c}\text { Three electrodes } \\
\text { measurements }\end{array}$ & {$[27]$} \\
\hline $\begin{array}{c}\text { Porous BDD } \\
\text { by thermal } \\
\text { treatment }\end{array}$ & $1 \mathrm{M}$ aqueous $\mathrm{Na}_{2} \mathrm{SO}_{4}$ & $\begin{array}{c}\mathrm{CV} \\
\left(10 \mathrm{mV} \cdot \mathrm{s}^{-1}\right)\end{array}$ & $140 \mu \mathrm{F} . \mathrm{cm}^{-2}$ & $\begin{array}{c}\text { Three electrodes } \\
\text { measurements }\end{array}$ & {$[22]$} \\
\hline $\begin{array}{l}\text { BDD on } \\
\text { CNTs }\end{array}$ & Phosphate Buffer Saline & $\mathrm{CV}\left(50\right.$ to $\left.200 \mathrm{mV} \cdot \mathrm{s}^{-1}\right)$ & $580 \mu \mathrm{F} . \mathrm{cm}^{-2}$ & $\begin{array}{c}\text { Three electrodes } \\
\text { measurements }\end{array}$ & [29] \\
\hline
\end{tabular}

The complex impedance plane plots (Cole-Cole) are shown in Fig. 5a and Fig.5c for aqueous and organic electrolytes, respectively. The complex impedance of the capacitor is equivalent to an $\mathrm{RC}$ circuit with $\mathrm{Z}=\mathrm{ESR}+(1 / \mathrm{jC} \omega)$. At low frequencies, impedance tends to behave as a pure capacitor, whereas at high frequencies, it behaves like a pure resistor. The transition between capacitive (quasi-vertical line) and resistive behavior (Warburg at approx. $45^{\circ}$ ) is observed at the "knee frequency" [35]. In the case of $1 \mathrm{M} \mathrm{H}_{2} \mathrm{SO}_{4}$ electrolyte, this transition frequency is clearly observed at around $5.8 \mathrm{~Hz}$. The transition is much less pronounced in the case of PC, but seems to appear at around $200 \mathrm{~Hz}$. The more vertical curve at low frequencies for the aqueous based electrolytes indicates that this device behaves more closely like an ideal capacitor than in the case of the organic electrolyte. The equivalent series resistances ESR were deduced from when the imaginary part equals zero. It was found to be $11 \Omega$ for the aqueous based electrolyte and $20 \Omega$ for PC. This resistance value corresponds to the intrinsic resistance of the porous diamond layer along with the current collector, the contact resistance between the active layer and the current collector, and the electrolyte. Since all components are the same here apart from the electrolyte, the higher ESR value here is attributed to the lower conductivity of the organic electrolyte over the aqueous one. Indeed, the conductivity of $\mathrm{TEABF}_{4}$ in $\mathrm{PC}$ is reported to be in the order of $14.5 \mathrm{mS}^{-\mathrm{cm}^{-1}}$ whereas that of $\mathrm{H}_{2} \mathrm{SO}_{4}$ solution is around $750 \mathrm{mS} . \mathrm{cm}^{-1}$ [36]. Since the power released by the super capacitor is inversely proportional to the ESR value, it is expected that this value shall be as low as possible, and in commercial carbon based capacitors usually below $1 \Omega$ [37]. Hence the values recorded in this work are considered to be fairly high, and attributed both to the intrinsically low conductivity of diamond, although highly doped, and possibly poor electrical interfacing with the substrate. However when compared to other porous diamond active electrodes, it is still reasonably low. For instance the series resistance of diamond on 
silicon nanowires in mixtures of ionic liquids and PC was reported to be above $100 \Omega$ [26], and also much above $100 \Omega . \mathrm{cm}^{-1}$ in the case of diamond honeycomb electrodes [24]. The equivalent distributed resistance (EDR), obtained from the linear projection of the almost vertical portion of the Cole-Cole plot to the real axis gives some indication regarding the ion diffusion through the diamond pores [10]. It was assessed to be $38 \Omega$ for the aqueous electrolyte and $120 \Omega$ for the organic one, respectively, which reflect the much larger cations radius in the case of the organic electrolyte. The Cole-Cole plots do not allow easy extraction of frequency information that can better be described by complex capacitance modelling of impedance data [35]. Thus the evolution of the real part $C^{\prime}(\omega)$ and imaginary part $C^{\prime \prime}(\omega)$ of the capacitance are plotted in Fig.5b and Fig.5d for both capacitors, respectively. The real capacitance values at $0.1 \mathrm{~Hz}$ are in fairly good agreement with the results from $\mathrm{CV}$ measurements $\left(0.96 \mathrm{mF} . \mathrm{cm}^{-2}\right.$ versus $1.31 \mathrm{mF} . \mathrm{cm}^{-2}$ in $1 \mathrm{M} \mathrm{H}_{2} \mathrm{SO}_{4}$ and $222 \mu \mathrm{F} . \mathrm{cm}^{-2}$ versus 420 $\mu \mathrm{F} . \mathrm{cm}^{-2}$ in $1 \mathrm{M} \mathrm{TEABF}_{4}$ in PC). In aqueous electrolyte, a frequency peak is observed in C" $(\omega)$ at approx. $0.5 \mathrm{~Hz}$ corresponding to the relaxation time $\tau_{0}$ of the device (2s). In the case of PC, the imaginary part plot seems also to reveal a peak centered at $50 \mathrm{~Hz}(\tau=20 \mathrm{~ms}) . \tau_{0}$ defines the limit between predominately resistive behavior at frequencies higher than $1 / \tau_{0}$ and capacitive behavior at lower frequencies. Low relaxation times are associated with low energy loss and fast response time of the supercapacitor (fast charge/discharge). In the case of organic electrolyte, the relaxation time is close to that measured e.g. with diamond coated glass fibers $(31.7 \mathrm{~ms})$ [28]. In the case of acid based electrolyte, the time constant is much higher. Generally speaking, aqueous electrolytes have much higher ionic conductivity, and thus provide lower resistance, as observed in this study, therefore they should also feature lower time constants than organic electrolytes [38]. Nevertheless, the larger the capacitance, the greater the time constant, which may explain the higher $\tau_{0}$ value found here in acidic electrolyte. 

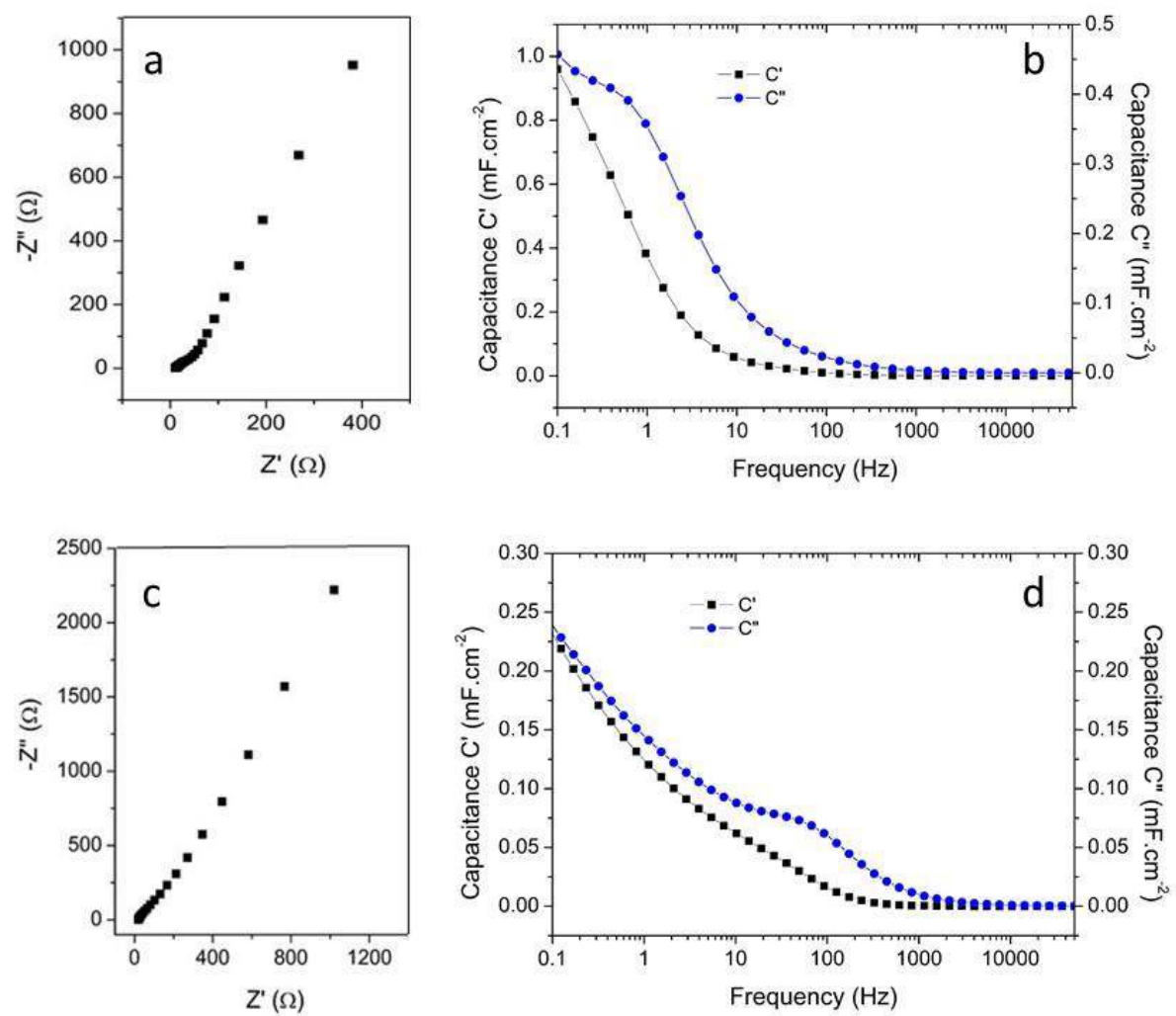

Fig.5. Cole-Cole plots and complex capacitance (real part C' and imaginary part C" are calculated according to equations from ref. [35]) for diamond pouch cell supercapacitor with $1 \mathrm{M} \mathrm{H}_{2} \mathrm{SO}_{4}$ in water (a and b) and $1 \mathrm{M} \mathrm{TEABF}_{4}$ in PC (c and d) electrolytes, respectively.

Galvanostatic charge discharge (GCD) was carried out in acid medium (Fig.6a) and propylene carbonate (Fig.6b) in the voltage range of $2 \mathrm{~V}$ at various current densities. The CDC curves are fairly linear at low current densities, which reveals a good capacitive behavior. Nevertheless, a clear ohmic drop at the turning point of charge-discharge as well as slight polarization of the electrodes can be observed. The ohmic drop increases with current density and indicates some energy loss due to internal DC resistance. The ohmic drop seems to be more pronounced for the organic electrolyte, as expected from previous ESR measurements, and results from the lower ionic mobility in PC. Overall the shape of the GCD curves is in agreement with the efficiency profiles of the devices as shown in fig.2c, suggesting moderate charge-discharge kinetics, presumably due to highly porous diamond network with somehow limited conductivity, and Faradic processes in the case of the aqueous based electrolyte, since dissociation of water was shown to appears from typically $1.5 \mathrm{~V}$. GCD was repeated over 10,000 cycles at current density of $500 \mu \mathrm{A} . \mathrm{cm}^{-2}$ in $1 \mathrm{M} \mathrm{H}_{2} \mathrm{SO}_{4}$ electrolyte and revealed no 
significant difference in charge-discharge profile, thus confirming the good stability of the device.

Ragone plot relating energy density to power density was calculated from the GCD measurements using the equations from reference [33] and shown in Fig.6c. The data were compared to that of diamond coated silicon nanowire thin films measured in ionic liquid as reported elsewhere [39]. The estimated maximum energy and power densities for PC are $0.17 \mu \mathrm{Wh} . \mathrm{cm}^{-2}$ and $200 \mu \mathrm{W} . \mathrm{cm}^{-2}$, respectively. Those values are very similar to the values obtained for diamond coated silicon nanowires in ionic liquid. In the case of the aqueous based electrolyte, the highest energy and power values are close to $1 \mu \mathrm{Wh} . \mathrm{cm}^{-2}$ and 700 $\mu \mathrm{W} . \mathrm{cm}^{-2}$, respectively. This is typically one order of magnitude larger in terms of energy stored and more than 5 times better in terms of power released when compared to diamond coated nanowires. The better performances of SPDia ${ }^{\mathrm{TM}}$ in water over SPDia ${ }^{\mathrm{TM}}$ in PC and diamond coated nanowires in ionic liquid reflects the lower ESR value and higher specific capacitance of the aqueous based electrolyte.
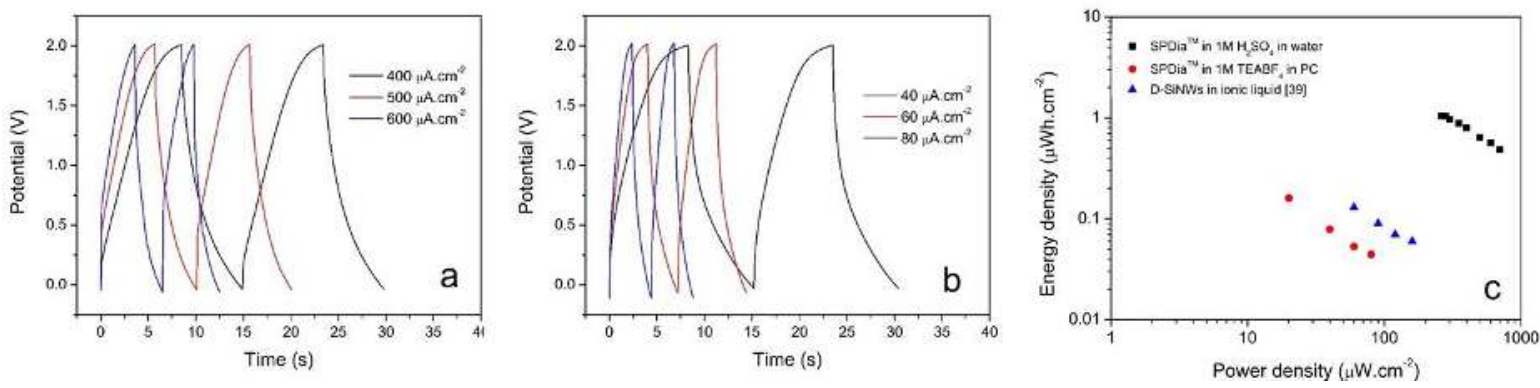

Fig.6. Examples of Galvanostatic Charge-Discharge (GCD) curves of diamond pouch cell supercapacitor with a. $1 \mathrm{M} \mathrm{H}_{2} \mathrm{SO}_{4}$ in water and b. $1 \mathrm{M} \mathrm{TEABF}_{4}$ in $\mathrm{PC}$ electrolytes, respectively, within a $2 \mathrm{~V}$ window; c. Ragone plot for the acidic and organic electrolytes, including also that for diamond coated silicon nanowires in ionic liquid (measured in 3electrode cell configuration) as reported in [39]

\section{Conclusions}

The first symmetrical thin film diamond supercapacitor on silicon mounted in pouch cell configuration was reported, using porous boron doped diamond grown over polypyrrole template as energy storage electrodes. This material was chosen because it was reported to be among the porous diamond coatings with the highest areal double layer capacitance, around 3 $\mathrm{mF} . \mathrm{cm}^{-2}$, and because it can be processed homogeneously over 4 inches silicon wafer with 
good control. Using diamond porous electrodes in supercapacitors allows taking advantage of their large potential window in water while benefiting from low ionic conductivity, low cost and low environmental impact of aqueous based electrolyte. Here the performances of the 3 $\mathrm{cm}^{-2}$ symmetrical pouch cell diamond supercapacitor were compared in the same configuration when an acidic and organic electrolytes were used. The large potential window in water, typically above $2 \mathrm{~V}$ was confirmed, along with a reasonably low series resistance in the low ohm range. The porous diamond material was grown over silicon for practical reasons, but this may not be optimum in the long term since the silicon substrate contributes to increasing the ESR and thus reduces the supercapacitor overall energy storage performances. A simple way to overcome this limitation would be to grow the porous diamond layer directly onto the charge collector, made e.g. of stainless steel, or any carbide forming metal compatible with low temperature diamond growth. Energy and power values close to $1 \mu \mathrm{Wh} . \mathrm{cm}^{-2}$ and $700 \mu \mathrm{W} . \mathrm{cm}^{-2}$ were recorded in water, thus surpassing by almost one order of magnitude the energy storage performances of similar carbon based devices using organic or ionic liquid electrolytes. Although such porous diamond coating are probably not competitive in terms of cost efficiency against other carbon materials when it comes to design high power bulk supercapacitors, they are certainly promising for thin film applications, where they could when combined with lithium batteries improve the power performances of the energy source for portable electronics applications.

Acknowledgement The authors would like to thank Guillaume Berthet for contact angle measurements. 


\section{References}

[1] J.-M. Tarascon, M. Armand, Issues and challenges facing rechargeable lithium batteries, Nature 414 (2001) 359-367.

[2] A. González, E. Goikolea, J. Andoni Barrena, R. Mysyk, Review on supercapacitors: Technologies and materials, Renewable and Sustainable Energy Reviews 58 (2016) 11891206.

[3] P. Simon, Y. Gogotsi, Materials for electrochemical capacitors, Nature Materials 7 (2008) 845-854.

[4] L. L. Zhang, X. S. Zhao. Carbon-based materials as supercapacitor electrodes. Chem. Soc. Rev., 38 (2009) 2520-2531.

[5] E. Frackowiak. Carbon materials for supercapacitor application. Phys. Chem. Chem. Phys., 9 (2007) 1774-1785.

[6] E. Frackowiak, F. Béguin, Carbon materials for the electrochemical storage of energy in capacitors, Carbon 39 (2001) 937-950.

[7] C. D. Lokhande, D. P. Dubal, O.-S. Joo, Metal oxide thin film based supercapacitors. Curr. Appl. Phys. 11 (2011) 255-270.

[8] W. Sun, X. Chen, Preparation and characterization of polypyrrole films for threedimensional micro supercapacitor, J. Power Sources 193 (2009) 924-929.

[9] G. P. Wang, L. Zhang, J. J. Zhang. A review of electrode materials for electrochemical supercapacitors. Chem. Soc. Rev., 41 (2012) 797-828.

*Corresponding author. Email: emmanuel.scorsone@cea.fr (Emmanuel Scorsone) 
[10] R. Kötz, M. Carlen, Principles and applications of electrochemical capacitors, Electrochimica Acta 45 (2000) 2483-2498.

[11] P. Azaïs, L. Duclaux, P. Florian, D. Massiot, M. Lillo-Rodenas, A. Linares-Solano, J. Peres, C. Jehoulet, F. Béguin. Causes of supercapacitors ageing in organic electrolyte. J Power Sources 171 (2007) 1046-1053.

[12] M. Ue, K. Ido, S. Mori. Electrochemical properties of organic liquid electrolytes based on quaternary onium salts for electrical double-layer capacitors. J Electrochem. Soc. 141 (1994) 2989-2996.

[13] P. Kurzweil, M. Chwistek. Electrochemical stability of organic electrolytes in supercapacitors: Spectroscopy and gas analysis of decomposition products. J Power Sources 176 (2008) 555-567.

[14] R. Y. Lin, P-L. Taberna, S. Fantini, V. Presser, C. R. Pérez, F. Malbosc, N. L. Rupesinghe, K. K, Teo, Y. Gogotsi, P.Simon. Capacitive energy storage from -50 to $100{ }^{\circ} \mathrm{C}$ using an ionic liquid electrolyte, J. Phys. Chem. Lett. 2 (2011) 2396-2401.

[15] A. Burke. R\&D considerations for the performance and application of electrochemical capacitors. Electrochim. Acta 52 (2007) 1083-1091.

[16] M. Galiński, A. Lewandowski, I. Stępniak. Ionic liquids as electrolytes, Electrochimica Acta 51 (2006) 5567-5580.

[17] M. Toupin, D. Bélanger, I. R. Hill, D. Quinn. Performance of experimental carbon blacks in aqueous supercapacitors, J. Power Sources 140 (2005) 203-210.

[18] L. Demarconnay, E. Raymundo-Piňero, F. Béguin. A symmetric carbon/carbon supercapacitor operating at $1.6 \mathrm{~V}$ by using a neutral aqueous solution, Electrochem. Commun. 12 (2010) 1275-1278.

[19] A. Fujishiman, Y. Einaga, T. Narasinga Rao, D. A. Tryk, Diamond Electrochemistry, Elsevier, Tokyo, 2005.

[20] Nianjun Yang, John S. Foord, Xin Jiang, Diamond electrochemistry at the nanoscale: A review, Carbon 99 (2016) 90-110.

[21] W. Smirnov, A. Kriele, N. Yang, C.E. Nebel, Aligned diamond nano-wires: Fabrication and characterisation for advanced applications in bio- and electrochemistry, Diamond \&Related Materials 19 (2010) 186-189.

*Corresponding author. Email: emmanuel.scorsone@cea.fr (Emmanuel Scorsone) 
[22] T. Kondo, Y. Kodama, S. Ikezoe, K. Yajima, T. Aikawa, M. Yuasa, Porous boron-doped diamond electrodes fabricated via two-step thermal treatment, Carbon 77 (2014) 783 - 789.

[23] H. Mehedi, J-C. Arnault, D. Eon, C. Hébert, D. Carole, F. Omnes, E. Gheeraert, Etching mechanism of diamond by Ni nanoparticles for fabrication of nanopores, Carbon 59 (2013) $448-456$.

[24] M. Yoshimura, K. Honda, R. Uchikado, T. Kondo, Tata N. Rao, D.A. Tryk, A. Fujishima, Y. Sakamoto, K. Yasui, H. Masuda, Electrochemical characterization of nanoporous honeycomb diamond electrodes in non-aqueous electrolytes, Diamond and Related Materials 10 (2001) 620-626.

[25] H. Zhuang, N. Yang, H. Fu, L. Zhang, C. Wang, N. Huang, X.Jiang, Diamond Network: Template-Free Fabrication and Properties, ACS Appl. Mater. Interfaces, 7 (9) (2015) 5384 5390.

[26] F. Gao, G. Lewes-Malandrakis, M.T. Wolfer, W. Muller-Sebert, P. Gentile, D. Aradilla, T. Schubert, C. E. Nebel, Diamond-coated silicon wires for supercapacitor applications in ionic liquids, Diamond and Related Materials 51 (2015) 1-6.

[27] F. Gao, M.T. Wolfer, C.E. Nebel, Highly porous diamond foam as a thin-film micro supercapacitor material, Carbon 80 (2014) 833-840.

[28] F. Gao, C.N. Nebel, Diamond-based supercapacitors: realization and properties, ACS Applied Materials\&Interfaces, DOI: 10.1021/acsami.5b07027

[29] C.Hébert, J-P Mazellier, E. Scorsone, M. Mermoux, P. Bergonzo, Boosting the electrochemical properties of diamond electrodes using carbon nanotube scaffolds, Carbon 71 (2014) $27-33$.

[30] C. Hébert, E. Scorsone, M. Mermoux, P. Bergonzo, Porous diamond with high electrochemical performance, Carbon 90 (2015) 102 - 109.

[31] R. Kiran, E. Scorsone, J. de Sanoit, J.-C. Arnault, P. Mailley, P. Bergonzo, Boron doped diamond electrodes for direct measurement in biological fluids: an in situ regeneration approach, J. Electrochem. Soc. 160, issue 1 (2013), H67-H73.

[32] R. Ansari, "Polypyrrole Conducting Electro Active Polymers: Synthesis and Stability Studies," E-Journal of Chemistry, Vol. 3, No. 13 (2006) 186-201.

*Corresponding author. Email: emmanuel.scorsone@cea.fr (Emmanuel Scorsone) 
[33] W-W Liu, X-B Yan, J-W Lang, C. Peng, Q-J Xue, Flexible and conductive nanocomposite electrode based on graphene sheets and cotton cloth for supercapacitor $\mathrm{J}$. Mater. Chem. 22 (2012) 17245.

[34] M. D. Stoller, R. S. Ruoff, Best practice methods for determining an electrode material's performance for ultracapacitors, Energy Environ. Sci. 3 (2010) 1294-1301.

[35] P.L. Taberna, C. Portet, P. Simon, Electrode surface treatment and electrochemical impedance spectroscopy study on carbon/carbon supercapacitors, Appl. Phys. A 82 (2006) 639-646.

[36] C. Zhong, Y. Deng, W. Hu, D. Sun, X. Han, J. Qiao, J. Zhang, Electrolytes for Electrochemical Supercapacitors, CRC Press, 2016, ISBN 9781498747554.

[37] S. Boukhalfa, K. Evanoff , G. Yushin, Atomic layer deposition of vanadium oxide on carbon nanotubes for high-power supercapacitor electrodes, Energy Environ. Sci. 5 (2012) 6872.

[38] R.A. Huggins, Energy storage - Fundamentals, Materials and Applications, Second edition, Springer, 2016, DOI 10.1007/978-3-319-21239-5.

[39] G. S. Gund , D. P. Dubal, D. Aradilla, W. Mueller-Sebert, G. Bidan, D. Gaboriau, P. Gentile, T. J. S. Schubert, J. Wimberg, S. Sadki, P. Gomez Romero, Diamond-coated silicon nanowires for enhanced micro-supercapacitor with ionic liquids, 2015 International Conference on Industrial Instrumentation and Control (ICIC) College of Engineering Pune, India. May 28-30, (2015) 1125-1128.

*Corresponding author. Email: emmanuel.scorsone@cea.fr (Emmanuel Scorsone) 


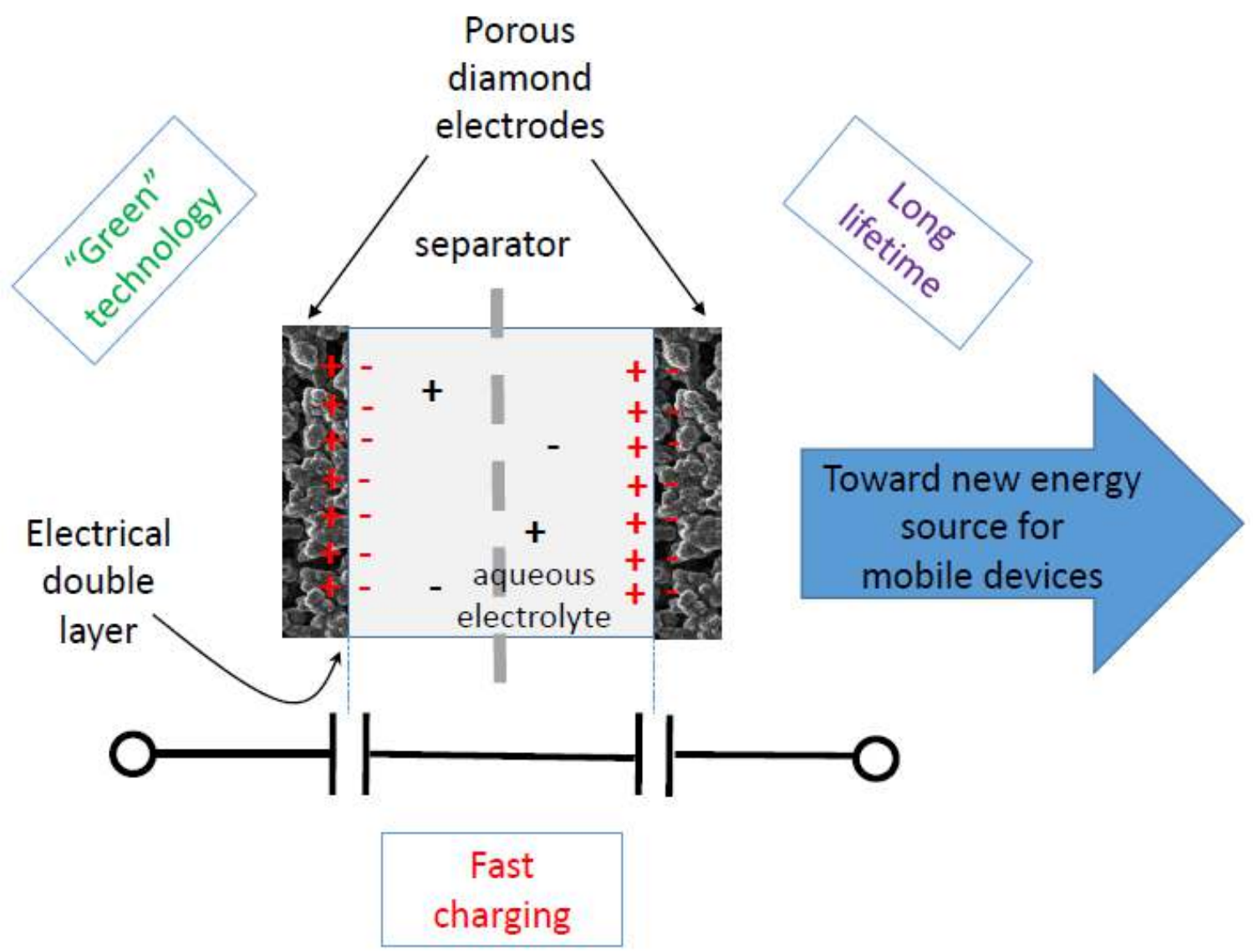

Graphical abstract 


\section{Highlights}

- A symmetrical pouch cell supercapacitor was fabricated using a highly porous diamond electrode material, grown over a polymer template on four inches substrates, and featuring a capacitance of $3 \mathrm{mF} . \mathrm{cm}^{-2}$

- The performances of the device were compared when using either an aqueous or organic based electrolytes

- Energy and power values close to $1 \mu \mathrm{Wh} . \mathrm{cm}^{-2}$ and $700 \mu \mathrm{W} . \mathrm{cm}^{-2}$ were recorded in water, thus surpassing by almost one order of magnitude the energy storage performances of similar carbon based devices using organic or ionic liquid electrolytes. 